\title{
Emotional Maturity Profile of Adult Family Members of Person with OCD
}

Jaya Bharti ${ }^{1}$

\section{ABSTRACT}

This is a cross-sectional study with the aim to study the constellation of emotional maturity profile of adult family members that interacts with and around clinically diagnosed cases of OCD. It also aimed to ascertain the overriding contribution of age and gender of key informants of OCD. In this study, 50 people with OCD, along with their 50 respective adult family members were taken on the basis of inclusion and exclusion criteria. Subjects were assessed using Sociodemographic and clinical sheet \& EMS. Appropriate statistics such as mean, standard deviation, $\mathrm{t}$ test were applied to analyse the data. The results of the study concluded that among the key informants of OCD, significance difference regarding emotional maturity and its various aspects were observed between male and female. Further, also noticed that mean scores of emotional instability, emotional regression, social maladjustment, personality disintegration, lack of independence and total emotional maturity were more in female key informants as compared to male key informants.

Keywords: Emotional Maturity, Adult Family, OCD

"Emotional maturity is a personality trait, the result of emotional development and the display of emotion appropriate to one's chronological age. It usually reflects increased emotional adjustment and emotional stability and the attainment of emotional selfregulation"

Emotional maturity defined as, "A process in which the personality is continually striving for greater sense of emotional health, both intra-psychically and intra- personally". In brief emotional maturity can be called as the process of impulse control through the agency of "self" or "ego". Emotional Maturity according to Dr. S. K. Mangal "Emotional Maturity is that characteristics of emotional behaviour that is generally attained by an adult after the expiry of his adolescence period"

\section{Becoming Empowered}

Emotional maturity is important if we are to be effective in our lives, and in our relationships. As you go along this upward spiritual path, look first within to your own immaturity or areas in

\footnotetext{
${ }^{1}$ Research Scholor, University of Lucknow, Uttar Pradesh \& India (C) 2015 I J Bharti; licensee IJIP. This is an Open Access Research distributed under the terms of the Creative Commons Attribution License (http://creativecommons.org/licenses/by/2.0), which permits unrestricted use, distribution, and reproduction in any Medium, provided the original work is properly cited.
} 


\section{Emotional Maturity Profile of Adult Family Members of Person with OCD}

which you'd like to be more empowered, if that applies to you. After you have been able to work with your own growth process, then are you able to help another who may be struggling. Sometimes God gives us a companions and soul mates to work through our parallel struggles together so that we can have a glimpse into the reality that we are not alone here as we learn what we came to learn in this life. We are all here to learn. Growing toward our highest self, and therefore following our higher path, requires the maturity of our souls. So, how do you recognize immaturity and maturity in yourself or others?

\section{The Emotionally Immature Person}

"When I was a child I talked like a child, I thought like a child, I reasoned like a child. When I became a man, I put childish ways behind me..."

There is a difference between being childish and child-like, to be child-like is to have a freedom of spirit, enjoying life in a carefree energy, and to have faith that you will be able to overcome your obstacles, entrusting your path to God as you understand it. It is actually mature to allow yourself to be child-like. Isn't that ironic? That is because being child-like keeps us open spiritually and receptive to the Divine path and flow of our lives.

\section{Signs of Emotional Immaturity:}

- They are selfish and self-cantered, much like a child. They do not think of the feelings of others so much as their own. Their own needs, wants and feelings take precedence over that of their partner's. They don't seem to notice (or maybe don't want to notice) how what they do affects their partner and even when they are shown how their behaviour affects their partner, they often will not apologize and make it right (since that requires maturity).

\section{Signs of Emotional Maturity:}

- They understand that they are responsible for how they feel and take responsibility for their actions, their words, and their attitudes and how those things affect the others around them. Expressions such as "I felt good when you " or "I felt hurt when you ___. Notice that they are taking ownership of their own feelings by saying "I felt..." not "you made me feel..."

\section{Family Involvement in OCD}

Living with someone with OCD can be challenging. It is difficult to watch someone you care so deeply for suffer so much. The anxiety is debilitating, the rituals are time consuming, and the impact OCD has on their life is devastating. Your attempts to help by assisting with OCD rituals can unexpectedly result in more anxiety and frustration instead of less, and often times you find yourself entangled in OCD symptoms instead of assisting your loved one out of them. 


\section{Emotional Maturity Profile of Adult Family Members of Person with OCD}

This pattern is vicious and can last for years. OCD therapists recognize the important role that family members often have in their loved ones OCD and involve them in treatment as a way of maximizing progress. They do this by teasing out how family dynamics have been affected by OCD and what accommodating behaviours family members are engaging in, educating the family about why accommodating behaviours don't work, and teaching them what to do instead.

If your family member has OCD or you have a close relationship with someone with OCD, you are likely impacted by their symptoms. Determining how you are involved, the extent to which you are involved, and the consequences of being involved is important. This information will facilitate goal setting, sets a baseline to help determine progress, and provides motivation for change.

Kaplan and Baron (1986) elaborated the characteristics of an emotionally mature person say that he has the capacity to withstand delay in satisfaction of needs, He has belief in long term planning and is capable of delaying or revising his expectations in terms of demands of situation. An emotionally mature student has the capacity to make effective adjustment with himself, members of his family, his peers in the school, society and culture. But maturity means not merely the capacity for such attitude and functioning but also the ability to enjoy them fully. Therefore, the emotionally mature student is not one who necessarily has resolved all conditions that aroused anxiety and hostility but it is continuously in process of seeing himself in clearer perspective, continual involved in a struggle to gain healthy integration of feeling, thinking and action. So emotional maturity can be called as the process of impulse control through the agency of self or ego.

\section{OPERATIONAL DEFINITIONS:}

\section{Obsessive Compulsive Disorder:}

DSM-5 Diagnostic Criteria for Obsessive-Compulsive Disorder (300.3)

Presence of obsessions, compulsions, or both:

\section{Obsessions are defined by (1) and (2):}

1. Recurrent and persistent thoughts, urges, or impulses that are experienced, at some time during the disturbance, as intrusive and unwanted, and that in most individuals cause marked anxiety or distress.

2. The individual attempts to ignore or suppress such thoughts, urges, or images, or to neutralize them with some other thought or action (i.e., by performing a compulsion).

\section{Compulsions are defined by (1) and (2):}

1. Repetitive behaviours (e.g., hand washing, ordering, checking) or mental acts (e.g., praying, counting, repeating words silently) that the individual feels driven to perform in response to an obsession or according to rules that must be applied rigidly. 


\section{Emotional Maturity Profile of Adult Family Members of Person with OCD}

2. The behaviours or mental acts are aimed at preventing or reducing anxiety or distress, or preventing some dreaded event or situation; however, these behaviours or mental acts are not connected in a realistic way with what they are designed to neutralize or prevent, or are clearly excessive.

\section{RATIONALE FOR THE STUDY}

The present study was planning to assess the emotional maturity profile of adult family members of obsessive compulsive disorder. Proposed study was aqueries and energetic effort to addressing the issues with integrated framework whereby concept of emotional maturity, problems and solution, factor associated with emotional maturity.

\section{OBJECTIVES}

The main objective of this study is to critically examine the family members of person with OCD and the challenges they face in living with the person and Following specific objectives were formulated:

1. To study the constellation of emotional maturity profile of adult family members that interact with and around clinically diagnosed cases of OCD

2. To ascertain the overriding contribution of age and gender of key informants of OCD.

\section{METHODOLOGY}

\section{Study Setting:}

The study was conducted in selected Psychiatric Hospital at Uttar Pradesh.

\section{Research design:}

This was a hospital-based, cross sectional \& exploratory research design.

\section{Population:}

The population of the present study was including adult members of patients who are diagnosed as obsessive compulsive disorder, on the basis of ICD-10 in a selected psychiatric hospital at Lucknow.

\section{Sample Size:}

Total subjects of adult family member of obsessive compulsive disorder 50

\section{Sampling Plan:}

Purposive sampling technique was used to select the samples for the study.

\section{Sampling Criteria-}

\section{Inclusion Criteria for Chronic Menally Ill Patients}

$\checkmark$ Age group ranging from 21-60 years

$\checkmark$ Patients diagnosed as obsessive compulsive disorder according to ICD-10

$\checkmark$ Duration of illness at least 2 years recruited to the study

2. Exclusion Criteria for Chronic Menally Ill Patients

$\checkmark$ Neurological disorders such as seizures, movement disorders, cerebral palsy

$\checkmark$ Recent or current medical illness 
$\checkmark$ Comorbidity with any other psychiatric disorder.

$\checkmark$ Use of any pharmacological intervention other than psychotropic drugs.

$\checkmark$ Life time history of head injury associated with loss of consciousness, seizures, neurological deficits, or surgical intervention.

\section{Inclusion Criteria for Caregivers}

$\checkmark$ Primary caregivers (Parents/Spouse/Sibling/Children)who are staying with the patient since the onset of illness are included.

$\checkmark$ Age group above 21 years

$\checkmark$ Living with the patient for at least last 1 year

$\checkmark$ Those who gave informed consent to participate in the study

\section{Exclusion Criteria for Caregivers}

$\checkmark$ Caregivers with psychiatric conditions, organic syndromes, mental retardation, substance dependence or chronic physical illness.

$\checkmark$ Those who did not give consent

\section{DATA COLLECTION PROCEDURES}

\section{Tools Used}

The following tools were used for the present study:

\section{A. SOCIODEMOGRAPHIC AND CLINICAL SHEET}

A semi-structured proforma will design to collect demographic information like age, sex, duration of marriage, etc. about the patients and their caregivers along with the clinical information like the age of onset, duration of illness, number of hospitalizations, etc. regarding the patient.

\section{B.EMOTIONAL MATURITY SCALE}

Emotional Maturity Scale (EMS; Singh and Bhargava, 1991). This scale measures a list of five broad factors:

1. Emotional Instability

2. Emotional regression

3. Emotional maladjustment

4. personality disintegration

5. Lack of independence.

It is a self-reporting five point scale. Items of the scale are in question form demanding information for each in any of the 5 options: Always, Mostly, Uncertain, Usually, Never. The items were scored as 5, 4,3,2,1 respectively. Therefore, the higher the score on the scale, greater the degree of the emotional immaturity and vice versa. The scale has total 48 items. There are 10 items per factor except the fifth factor which has 8 items. The highest possible score for the first 4 areas are 50 and the lowest is 10 while for the fifth factor the highest score is 40 and lowest is 8.(For all the first 4 factors the extremely unstable range from 10-20( for 5th factor-816),moderately unstable from 21-30(17-24), unstable from 31-40(25-32),stable from 41-50(33- 


\section{Emotional Maturity Profile of Adult Family Members of Person with OCD}

40)). Reliability of the scale was determined by test retest reliability which was 0.75 and internal consistency for various factors ranged from .42-.86.

\section{Ethical Issues}

1- A fully informed consent was taken from all participants in the study prior to data collection.

2- The participation or non-participation of the subjects did not alter the services offered to them at the hospital.

3- Subjects had the right to withdraw from the study at any point of time during the course of the study.

4- The confidentiality of the subject was maintained through the course of the study and was shared with the treating team when deemed beneficial for the patient's management

\section{METHOD OF DATA COLLECTION}

The study was approved by the hospitals ethics committee, and all subjects gave written informed consent to participate. Person with OCD and their adult family member were selected by purposive sampling on the basis of inclusion and exclusion criteria from out patients of the hospitals. Detailed data was collected on the socio-demographic and clinical data sheet designed for the purpose. Subjects were assessed Emotional Maturity Scale (EMS; Singh and Bhargava, 1991).

\section{ANALYSIS AND INTERPRETATION}

Table-1: Shows the Mean Scores of Various Type of Emotional Maturity According To Gender to Adult Family Members of OCD

\begin{tabular}{|c|c|c|c|c|c|c|c|c|c|c|c|c|c|}
\hline \multirow[t]{2}{*}{ Gender } & \multirow{2}{*}{$\begin{array}{l}\text { No. } \\
\text { of } \\
\text { Cases }\end{array}$} & \multicolumn{2}{|c|}{$\begin{array}{l}\text { Emotional } \\
\text { Instability }\end{array}$} & \multicolumn{2}{|c|}{$\begin{array}{l}\text { Emotional } \\
\text { Regression }\end{array}$} & \multicolumn{2}{|c|}{$\begin{array}{l}\text { Social } \\
\text { Malad. }\end{array}$} & \multicolumn{2}{|c|}{$\begin{array}{l}\text { Personality } \\
\text { Disinti. }\end{array}$} & \multicolumn{2}{|c|}{$\begin{array}{l}\text { Lack of } \\
\text { Inddep. }\end{array}$} & \multicolumn{2}{|l|}{$\begin{array}{l}\text { Total } \\
\text { E.M }\end{array}$} \\
\hline & & Mean & SD & Mean & SD & Mean & SD & Mean & SD & Mean & SD & Mean & SD \\
\hline Male & 38 & $\begin{array}{l}21.4 \\
6\end{array}$ & $\begin{array}{l}5.5 \\
3\end{array}$ & $\begin{array}{l}21.8 \\
6\end{array}$ & $\begin{array}{l}4.9 \\
5\end{array}$ & $\begin{array}{l}21.9 \\
4\end{array}$ & $\begin{array}{l}4.9 \\
2\end{array}$ & $\begin{array}{l}22.0 \\
0\end{array}$ & $\begin{array}{l}3.9 \\
1\end{array}$ & $\begin{array}{l}19.8 \\
1\end{array}$ & $\begin{array}{l}4.6 \\
1\end{array}$ & $\begin{array}{l}106 . \\
1\end{array}$ & $\begin{array}{l}17.3 \\
3\end{array}$ \\
\hline Female & 12 & $\begin{array}{l}28.0 \\
7\end{array}$ & $\begin{array}{l}7.5 \\
3\end{array}$ & $\begin{array}{l}26.0 \\
7\end{array}$ & $\begin{array}{l}6.9 \\
9 \\
\end{array}$ & $\begin{array}{l}24.6 \\
6\end{array}$ & $\begin{array}{l}5.0 \\
2 \\
\end{array}$ & $\begin{array}{l}26.3 \\
1\end{array}$ & $\begin{array}{l}4.6 \\
9\end{array}$ & $\begin{array}{l}21.3 \\
1\end{array}$ & $\begin{array}{l}5.8 \\
1 \\
\end{array}$ & $\begin{array}{l}126 . \\
5\end{array}$ & $\begin{array}{l}24.1 \\
0\end{array}$ \\
\hline Total & 50 & $\begin{array}{l}23.0 \\
5\end{array}$ & $\begin{array}{l}6.7 \\
2\end{array}$ & $\begin{array}{l}22.7 \\
7\end{array}$ & $\begin{array}{l}5.7 \\
8\end{array}$ & $\begin{array}{l}22.6 \\
1\end{array}$ & $\begin{array}{l}5.1 \\
1\end{array}$ & $\begin{array}{l}23.0 \\
3\end{array}$ & $\begin{array}{l}4.5 \\
3\end{array}$ & $\begin{array}{l}20.1 \\
5\end{array}$ & $\begin{array}{l}4.9 \\
5\end{array}$ & $\begin{array}{l}112 . \\
8\end{array}$ & $\begin{array}{l}20.8 \\
6\end{array}$ \\
\hline \multicolumn{2}{|l|}{$\mathrm{t}$} & \multicolumn{2}{|c|}{2.305} & \multicolumn{2}{|c|}{2.334} & \multicolumn{2}{|l|}{1.648} & \multicolumn{2}{|l|}{3.166} & \multicolumn{2}{|l|}{0.929} & \multicolumn{2}{|c|}{3.075} \\
\hline \multicolumn{2}{|l|}{$\mathrm{p}$} & \multicolumn{2}{|c|}{$<0.05$} & \multicolumn{2}{|c|}{$<0.05$} & \multicolumn{2}{|c|}{$>0.05$} & \multicolumn{2}{|c|}{$<0.05$} & \multicolumn{2}{|c|}{$>0.05$} & \multicolumn{2}{|c|}{$<0.05$} \\
\hline
\end{tabular}

Table no. 1 shows the mean scores of various type of emotional maturity according to gender of adult family member of OCD. The emotional maturity scores were observed of high among female as compared to male in all type of emotional maturity i.e. emotional instability, emotional 


\section{Emotional Maturity Profile of Adult Family Members of Person with OCD}

regression, social maladjustment, personality disintegration, lack of independence and total maturity.

Statistically significance difference regarding the mean scores in various type of emotions between male and female except social maladjustment and lack of independence scores were observed between male and female at $5 \%$ level of significance.

Table-2: Shows the Mean Scores of Various Type of Emotional Maturity According To Age of Adult Family Members of OCD

\begin{tabular}{|c|c|c|c|c|c|c|c|c|c|c|c|c|c|}
\hline $\begin{array}{l}\text { Age In } \\
\text { Years }\end{array}$ & $\begin{array}{l}\text { No.of } \\
\text { Cases }\end{array}$ & \multicolumn{2}{|c|}{$\begin{array}{l}\text { Emotional } \\
\text { Instability }\end{array}$} & \multicolumn{2}{|c|}{$\begin{array}{l}\text { Emotional } \\
\text { Regression }\end{array}$} & \multicolumn{2}{|l|}{$\begin{array}{l}\text { Social } \\
\text { Malad. }\end{array}$} & \multicolumn{2}{|c|}{$\begin{array}{l}\text { Personality } \\
\text { Disinti. }\end{array}$} & \multicolumn{2}{|c|}{$\begin{array}{l}\text { Lack of } \\
\text { Inddep. }\end{array}$} & \multicolumn{2}{|l|}{$\begin{array}{l}\text { Total } \\
\text { E.M }\end{array}$} \\
\hline & & Mean & SD & Mean & SD & Mean & SD & Mean & SD & Mean & SD & Mean & SD \\
\hline$>50$ & 39 & 23.10 & 6.49 & 22.72 & 5.89 & 22.15 & 4.88 & 23.26 & 4.40 & 22.28 & 4.65 & 111.5 & 20.84 \\
\hline$<50$ & 11 & 22.91 & 7.40 & 23.45 & 5.30 & 24.18 & 5.62 & 22.27 & 4.92 & 19.82 & 5.98 & 112.6 & 20.96 \\
\hline \multicolumn{2}{|l|}{$\mathrm{t}$} & \multicolumn{2}{|l|}{0.094} & \multicolumn{2}{|l|}{0.0370} & \multicolumn{2}{|l|}{1.180} & \multicolumn{2}{|l|}{0.643} & \multicolumn{2}{|l|}{0.272} & \multicolumn{2}{|l|}{0.159} \\
\hline \multicolumn{2}{|l|}{ p } & \multicolumn{2}{|l|}{$>0.05$} & \multicolumn{2}{|l|}{$>0.05$} & \multicolumn{2}{|l|}{$>0.05$} & \multicolumn{2}{|l|}{$>0.05$} & \multicolumn{2}{|l|}{$>0.05$} & \multicolumn{2}{|l|}{$>0.05$} \\
\hline
\end{tabular}

Table no. 2 shows the mean scores of various type of emotional maturity according to age of adult family member of OCD. The total emotional maturity scores were found to be more among the adult family members of OCD having the age above 50 years as compared to cases having the age below 50 years. The mean scores of emotional instability, personality disintegration, lack of independence were more among the cases having the age below 50 years as compared to cases having the age above 50 years while the mean score of emotional regression and social maladjustment were more among the cases having age more than 50 years as compare to cases having the age below 50years. However the mean difference of various type of emotional were found to be insignificant between cases having the age below 50years with the age above 50 years even at $5 \%$ level of significance.

\section{CONCLUSION}

By observing the analysis of the data it could be included that among the key informants of OCD, significance difference regarding emotional maturity and its various aspects were observed between male and female. Further, also noticed that mean scores of emotional instability, emotional regression, social maladjustment, personality disintegration, lack of independence and total emotional maturity were more in female key informants as compared to male key informants.

\section{LIMITATIONS}

1. Sample size was modest, which makes it difficult to generalize the result.

2. Random sampling was not done.

3. It was a Cross sectional study. 


\section{REFERENCES}

APA. American Psychiatric Association. Diagnostic and Statistical Manual of Mental Disorders, Fifth Edition (DSM-5®). American Psychiatric Pub. 2013.

Clark DA, Beck AT. Clark-Beck Obsessive Compulsive Inventory. San Antonio, TX: The Psychological Corporation; 2002.

Kellner M. Drug treatment of obsessive-compulsive disorder. Dialogues in clinical neuroscience.2010; 12(2):187-197

Veale D, Roberts A. Obsessive-compulsive disorder. BMJ (Clinical research ed.). 2014; 348:g2183.

\section{Webs}

http://ascending-path.com/articles-and-writings/developing-emotional-maturity-Know thyself” Socrates, Greek Philosopher

http://beyondocd.org-Diagnostic and Statistical Manual of Mental Disorders, Fifth Edition, (Copyright 2013). American Psychiatric Association.

http://www.ocdmassachusetts.org-by Denise Egan Stack, LMHC 